\title{
Limitation of joint mobility (cheiroarthropathy) in adult noninsulin-dependent diabetic patients
}

\author{
M. A. FITZCHARLES, S. DUBY, R. W. WA D DELL,${ }^{*}$ E. BANKS, \\ A N D J. KARSH
}

From the Rheumatic Diseases Unit and *Metabolic Day Centre, Royal Victoria Hospital, McGill University, Montreal, Quebec, Canada

SUMMARY Joint mobility was assessed in 80 consecutive adult noninsulin-dependent diabetic (NIDD) patients and 47 nondiabetic controls matched for age and sex. Impairment of mobility was observed in 36 NIDD patients but only 7 controls $(p<0 \cdot 01)$. There were no significant differences between diabetic patients with and without impaired mobility with regards to age, duration of diabetes, mean daily insulin dose, or overall diabetic control as assessed by the measurement of glycosylated haemoglobin $\left(\mathrm{HbA}_{1} \mathrm{C}\right)$. However, NIDD patients with impaired joint mobility had a significantly increased frequency of microvascular disease, as shown by retinopathy and/or nephropathy $(42 \%$ versus $22 \%, \mathrm{p}<0.05)$, were more often on insulin treatment $(86 \%$ versus $63 \%$, $\mathrm{p}<0.05$ ) and more frequently had additional rheumatic disorders such as Dupuytren's contracture and osteoarthritis ( $36 \%$ versus $18 \%, p<0.05)$. In addition tight waxy skin over the phalanges was commonly associated with impaired mobility ( $58 \%$ versus $22 \%, \mathrm{p}<0.01)$. Limitation of joint mobility was most prominent in the hands but caused no functional impairment. This finding may be an additional marker of microvascular disease in the adult diabetic patient.

Limited extension of the small joints of the hand in association with tight, waxy overlying skin has been described in up to $30 \%$ of juveniles with insulindependent diabetes. ${ }^{1-3}$ This condition, termed juvenile diabetic cheiroarthropathy, has been described only infrequently in adults. The pathogenesis of diabetic cheiroarthropathy is poorly understood. In children it is most commonly associated with microvascular disease, at times predating the onset of microangiopathy of the eyes or kidneys. This suggests that the vascular abnormality characteristic of diabetes may be an important factor also in the development of limited joint mobility. In addition in poorly controlled insulin-dependent diabetic children enhanced cross-linking of connective tissue collagen may further contribute to the development of the lesion. ${ }^{3}$ Indeed the thickened skin and bowed fingers in cheiroarthropathy are remarkably similar to the appearance of the skin and fingers of individuals with early systemic sclerosis, where the development of bowed fingers appears to be secon-

Accepted for publication 5 May 1983.

Correspondence to Dr Mary-Ann Fitzcharles, Division of Rheumatology, Royal Victoria Hospital, 687 Pine Avenue West, Montreal, Quebec H3A 1A1, Canada. dary to collagen proliferation in the skin, subcutaneous tissues, and muscle. ${ }^{4}$

We undertook to determine the prevalence of limited joint mobility in adult noninsulin-dependent diabetic (NIDD) patients, and to investigate its association with the presence of complications of diabetes.

\section{Materials and methods}

One hundred consecutive diabetic patients attending a diabetic clinic, and 47 age and sex matched controls without a known history of diabetes mellitus, were examined. Of the diabetic patients 80 were NIDD and 20 had insulin-dependent diabetes (IDD) as classified by the National Diabetes Data Group. ${ }^{5}$ This study was confined to an evaluation of the 80 patients with NIDD. Patients were considered to be NIDD if there was no previous history of ketosis. they had not suffered severe weight loss, and the indication for insulin was for correction of symptomatic or persistant hyperglycaemia.

Joint mobilty was assessed by the method of Rosenbloom et al. ${ }^{1}$ To demonstrate joint mobility of the fingers the patients attempted to approximate palmar surfaces and fingers with the fingers splayed. 
If the patients could not approximate the palmar surfaces completely, the examiners attempted to extend the fingers passively. The angle of extension of the proximal interphalangeal joint was measured, and a value of less then $0^{\circ}$ (failure to extend fully) was taken to be abnormal. Extension of the metacarpophalangeal joint of each index finger with the hand resting on a flat surface was also measured. If active extension of this joint was less than $30^{\circ}$ above the horizontal, the examiner passively extended the joint, accepting an angle of less than $30^{\circ}$ with assisted extension as abnormal. The effect of wrist flexion on interphalangeal joint extension, a manoeuvre to assess the contribution of flexor muscle and tendon shortening, was studied by approximating dorsal surfaces of the hands with the wrists flexed to $90^{\circ}$. Maximal extension of the wrists and elbows was measured as well as the range of motion of shoulders and of the cervical and lumbar spine.

Joint limitation was classified according to the criteria of Rosenbloom et al. ${ }^{1}$ as slight if there was impaired extension of either proximal interphalangeal joints or metacarpophalangeal joints, moderate if there was reduced extension of both proximal interphalangeal joints and metacarpophalangeal joints, and severe if there was impaired extension of proximal interphalangeal joints and metacarpophalangeal joints and limitation of a large joint.

The presence of Dupuytren's contracture of the palmar fascia, or Bouchard's or Heberden's nodes as evidence of osteoarthritis of the hands, was noted. Skin tenting was assessed by pinching the skin over the dorsum of the hand and proximal phalanges and was recorded as being normal or reduced. A waxy appearance of the skin of the hands was recorded. An enquiry was made regarding functional disturbances noted by the patient.

The following variables were noted for correlation with reduction of joint mobility: age, sex, duration of diabetes mellitus, medications, current insulin dosage, and diabetic control as estimated by glycosylated haemoglobin $\left(\mathrm{Hb} \mathrm{A}_{1} \mathrm{C}\right)$ with the Isolab fast $\mathrm{Hb}$ test system (Isolab Inc., Akron, Ohio). Particular attention was paid to a history of previous joint disease or soft tissue rheumatism.

The presence of diabetic retinopathy was determined by fundiscopic examination by an ophthalmologist unaware of the patient's clinical status. Fundal status was classified as $I-$ no retinopathy, II-background retinopathy (dot haemorrhages, exudates), and III-severe proliferative retinopathy.

In the presence of persistent proteinuria on routine urine testing (Dipstix), a 24-hour urine collection for estimation of protein and creatinine clearance was performed. In grading renal involvement I was normal renal function, II was proteinuria of over 500 $\mathrm{mg} /$ day, and III was proteinuria and impaired creatinine clearance $(<60 \mathrm{ml} / \mathrm{min})$.

The presence of microvascular disease was defined by evidence of diabetic retinopathy and/or renal disease (classes II or III).

The control group of people who had no known history of diabetes was drawn from hospital workers, family members accompanying patients to hospital clinics, and a local old-age home. They were not examined for the presence of cryptic diabetes, retinopathy, or renal disease. Joint mobilty was assessed as previously described, and they were questioned about the presence of any previous rheumatic symptoms.

Statistical significances were determined by the chi-squared method and Student's $t$-test.

\section{Results}

Of the 100 patients 80 were classified as having noninsulin-dependent diabetes, and they form the basis of the following analysis. Limitation of joint mobility was significantly more frequent in the diabetic patients, $36 / 80$, than in the controls $7 / 47$ $(p<0 \cdot 01)$. Nine diabetic patients were classified as having severe joint limitation, 13 moderate limitation, and 14 slight limitation. The 7 control patients with joint limitation had only slight impairment of joint mobility. The statistical analyses of the subgroups of patients with limited mobility revealed no significant differences between groups for all the variables studied. Consequently NIDD patients with impaired mobility were assessed as one group (group A) and compared with NIDD patients with normal joint mobility (group B).

There were no significant differences between groups A and B with regard to distribution of age, sex, duration of diabetes, mean daily insulin dosage, or control of diabetes as assessed by $\mathrm{Hb} \mathrm{A}_{1} \mathrm{C}$ (Table 1).

Several clinical variables were found more commonly in diabetic patients with limited mobility (Table 2). A total of 64 patients were receiving insulin for control of diabetes. In group A 36 patients $(86 \%)$ were on insulin as compared with $28(63 \%)$ in group B. This finding was significant $(p<0.05)$.

Seventy NIDD diabetic patients were examined for evidence of microvascular disease, and it was found in 23 .

Fifteen of 35 patients (42\%) in group $A$ and $8 / 35$ $(22 \%)$ in group B had this complication of diabetes $(p<0 \cdot 05)$. Retinal disease was the commonest manifestation of microvascular disease, being found in $36 \%$ of group A and $17 \%$ of group B. Renal disease was present in $27 \%$ of group A and $16 \%$ of group B. 
Table 1 Parameters not distinguishing between group $A$ and group $B$ diabetic patients

\begin{tabular}{llll}
\hline & $\begin{array}{l}\text { Group A } \\
(n=36)\end{array}$ & $\begin{array}{l}\text { Group B } \\
(n=44)\end{array}$ & $p$ \\
\hline $\begin{array}{l}\text { Age (years) } \\
\text { Sex, male/ female }\end{array}$ & $63 \cdot 16 \pm 11 \cdot 11$ & $58 \cdot 37 \pm 10 \cdot 46$ & NS \\
$\begin{array}{c}\text { Duration diabetes } \\
\text { mellitus (years) }\end{array}$ & $11 \cdot 68 \pm 9.96$ & $11 \cdot 31 \pm 9 \cdot 76$ & NS \\
$\begin{array}{c}\text { Mean daily insulin } \\
\text { dose (units) }\end{array}$ & $37 \cdot 77 \pm 24.67$ & $37 \cdot 17 \pm 23.57$ & NS \\
$\begin{array}{c}\text { Glycosylated } \\
\text { haemoglobin }\end{array}$ & $10 \cdot 28 \pm 2 \cdot 18$ & $10 \cdot 06 \pm 2 \cdot 13$ & NS \\
\hline
\end{tabular}

NS=not significant.

Table 2 Parameters distinguishing between group $A$ and group $B$ diabetic patients

\begin{tabular}{llll}
\hline & $\begin{array}{l}\text { Group A } \\
(n=36)\end{array}$ & $\begin{array}{l}\text { Group B } \\
(n=44)\end{array}$ & \\
\hline $\begin{array}{l}\text { Insulin-requiring } \\
\text { patients }\end{array}$ & $36(86 \%)$ & $28(63 \%)$ & $\mathrm{p}<0.05$ \\
$\begin{array}{c}\text { Microvascular } \\
\text { disease* }\end{array}$ & $15 / 35(42 \%)$ & $8 / 35(22 \%)$ & $\mathrm{p}<0.05$ \\
$\begin{array}{c}\text { Additional rheu- } \\
\text { matic co m- }\end{array}$ & $13(36 \%)$ & $8(18 \%)$ & $\mathrm{p}<0.05$ \\
$\begin{array}{c}\text { plaints } \\
\text { Tight waxy skin }\end{array}$ & $21(58 \%)$ & $10(22 \%)$ & $\mathrm{p}<0.01$ \\
\hline
\end{tabular}

* Only 70 patients were thoroughly examined for presence of microvascular disease.

There was a history of additional rheumatic complaints in 21 diabetic patients, of whom 13 had impaired joint mobility, and in 18 of the 47 control patients. The rheumatic complaints included a history of shoulder bursitis, tendinitis, epicondylitis, low back or cervical spine pain, osteoarthritis, and Dupuytren's contracture. A history of previous rhe umatic complaints was given with equal frequency in the control and diabetic groups. But additional rheumatic complaints were significantly more common in diabetic patients in group A than in group B $(\mathrm{p}<0.05)$.

Tight waxy skin over the proximal phalanges was present in $21(58 \%)$ patients in group $\mathrm{A}$ and 10 $(22 \%)$ patients in group $B$. The difference between the 2 groups was significant $(p<0 \cdot 01)$.

\section{Discussion}

Various common rheumatic complaints have been noted to be more prevalent than usual in patients with diabetes mellitus. ${ }^{6}$ Limited joint mobility or diabetic cheiroarthropathy should be added to this lengthy list, occuring both in juvenile ${ }^{1-3}$ and adult NIDD populations. ${ }^{7}$ While an explanation for the development of rheumatic lesions in diabetes is lacking, it has been assumed that they are a consequence of the metabolic abnormalities that characterise diabetes mellitus. The association of cheiroarthropathy with a higher frequency of angiopathy and insulin therapy suggests that this lesion also is a valid indicator of the severity of diabetes.

We did not find a higher frequency of additional rheumatic complaints in the diabetic patients than in the normal controls. This finding is at variance with the commonly held view that there is an increased frequency of soft tissue rheumatism in diabetic patients. We also could not confirm the observation of Rosenbloom et al. ${ }^{1}$ in juvenile diabetes of a strong association between the increasing severity of joint limitation and the increased prevalence of microvascular disease. This discrepancy may reflect, in part, differences in the numbers of patients studied, as well as possible clinical differences between juvenile onset and adult NIDD populations.

Undoubtedly the development of diabetic cheiroarthropathy is complex and multifactorial. The possible sites in the tissues leading to impaired mobility include alterations of the structures in the hand such as intrinsic muscle, joint capsule, and subcutaneous tissues and/or alterations of structures extrinsic to the hand such as the long flexor muscles and flexor tendons of the forearm. In each case alterations in these structures may be the consequence of the interaction of vascular ischaemia, alterations in the structure or composition of collagen, and alterations induced by a neuropathic process. Abnormalities in vessels, collagen, and nerves have been well described in diabetes with the common pathway of derivation reflecting the metabolic abnormalities of the disease.

Evidence for a neuropathic aetiology has been offered by Jung et al. ${ }^{7}$ who noted joint contractures in 23 of 57 adult diabetic patients and demonstrated an association of the lesion with delayed median nerve conduction and intrinsic hand muscle wasting. We did not have the opportunity to perform nerve conduction studies in our patients.

A diffuse muscle abnormality, either primary to diabetes or secondary to vasculopathy, may also be a factor leading to joint contracture. Most diabetic patients have thickening of the capillary basement membrane in the quadriceps femoris muscle. ${ }^{8}$ The appearance of joint contractures in diabetes is similar to that observed in early systemic sclerosis, which is noted for its diffuse vascular abnormality. Palmer $e t$ al. ${ }^{4}$ recorded bowed fingers as an early sign of systemic sclerosis, which they attributed to collagen infiltration in the forearm flexor muscles leading to shortening and tethering of the forearm flexor muscles and tendons. When the limited finger extension is due to tendon shortening, full flexion of the wrists should allow full extension of the fingers. Correction of limited extension by wrist flexion in a 
minority of our patients suggested that flexor muscle involvement may be responsible for cheiroarthropathy. Shortening of finger tendons may also be seen in Dupuytren's contracture when the process extends beyond the palmar fascia along the tendons of the forearm. ${ }^{9}$

Another possible mechanism of impaired joint mobility seen mainly in the hands of diabetic patients is thickening of the skin and subcutaneous tissue secondary to microangiopathy of dermal and subcutaneous vessels. The pathogenesis of diabetic microangiopathy is not well understood. The fundamental morphological change is thickening of the capillary basement membrane. This has been observed in many tissues, including the quadriceps femoris muscle, ${ }^{8}$ but has been most extensively studied in the capillary basement membrane of the renal glomerulus. ${ }^{10}$ Electron microscopic studies indicate that the onset of basement membrane changes coincides with the onset of metabolic disturbances of diabetes mellitus and that the changes progress with the duration of the disease. ${ }^{11.12}$ Enzymatic steps in the synthesis of basement membrane are susceptible to environmental influences, and thus the metabolic derangement of diabetes mellitus might alter the rate of collagen synthesis or the nature of the end product. Chang et al. ${ }^{13}$ have demonstrated increased collagen cross-linkage in experimental diabetes which could be reversed by $D$-penicillamine. Increased nonenzymatic glycosylation of collagen ${ }^{3}$ in the hyperglycaemic environment of the diabetic may alter the intrinsic properties of connective tissue, thereby causing lesions in the skin, joints, capsules, and other tissues.

In the light of present knowledge of the pathogenesis of complications of diabetes mellitus we would postulate that microangiopathy of dermal and subcutaneous vessels is an important underlying mechanism in the development of impaired joint mobility in our patients. This microangiopathy could lead to low-grade ischaemia of tissues with resulting fibrosis, manifesting clinically as tightened waxy skin over the digits. Alternatively the microangiopathy may simply reflect a diffuse alteration in collagen which is also evident in the tissues of the hand. In most patients with flexed fingers the abnormality was not reducible by flexion of the wrists, confirming that cheiroarthropathy was not simply a problem of flexor muscles. Of interest was the observation that, in spite of moderate limitation of mobility of finger joints, patients experienced little functional impairment. Thus the prevalence of the finding far exceeded any complaints expressed by the patients.

We have shown that limited joint mobility is a common finding in adult noninsulin-dependent diabetic patients and is associated with the presence of microvascular disease. In the absence of a prospective study it is not possible to determine whether this finding predates the appearance of renal or ophthalmic disease or whether careful blood glucose control with insulin therapy can reduce the rate of development of the lesion. However, we would suggest that this rapid and easy office assessment could form part of the routine assessment of diabetic patients, and that the presence of impaired joint mobility should alert the physician to the likely presence of microvascular disease.

We are grateful to the Canadian Arthritis Society for financial support and to Mrs Linda Carfagnini and Miss Claudia Povajnuk for secretarial assistance.

\section{References}

1 Rosenbloom A L, Silverstein J H, Lezotte D C, Richardson K, McCallum M. Limited joint mobility in childhood diabetes mellitus indicates increased risk for microvascular disease. $N$ Engl J Med 1981; 305: 191-4.

2 Grigic A, Rosenbloom A L, Weber FT, Giordano B, Malone J I, Shuster J J. Joint contracture-common manifestations of childhood diabetes mellitus. J Pediatr 1976; 88: 584-8.

3 Buckingham B A, Hitto J, Sandbury C, Keens T, Kaufman F, Landing B. Scleroderma-like syndrome and non-enzymatic glycosylation of collagen in children with poorly controlled insulin dependent diabetes (IDDM). Pediatr Res 1981; 15: 626 (abstr).

4 Palmer D G, Hale G M, Grennan D M, Pollack M: Bowed fingers: a helpful sign in the early diagnosis of systemic sclerosis. J Rheumatol 1981; 8: 66-72.

5 National Diabetes Data Group. Classification and diagnosis of diabetes mellitus and other categories of glucose intolerance. Diabetes 1979; 28: 1039-57.

6 Gray R G, Gottlieb N L. Rheumatic disorders associated with diabetes mellitus: literature review. Semin Arthritis Rheum 1976; 6: 19-34.

7 Jung Y, Hohmann T, Gerneth J, et al. Diabetic hand syndrome. Metabolism 1971; 20: 1008-15.

8 Kilo C, Vogler N, Williamson J R. Muscle capillary basement membrane changes related to aging and to diabetes mellitus. Diabetes 1972; 21: 881-98.

9 McFarlane R M. Patterns of diseased fascia in the fingers in Dupytren's contracture. Plast Reconstr Surg 1974; 54: 31-44.

10 Spiro R G. Biochemistry of the renal glomerulus basement membrane and its alterations in diabetes mellitus. $N$ Engl $\mathrm{J}$ Med 1973; 288: 1337-42.

11 Osterby $H R$, Lundback $K$. The basement membrane morphology in diabetes mellitus. In: Ellenberg M, Rifkin H, eds. Diabetes mellitus theory and practice. New York: McGraw-Hill, 1970: 178-204.

12 Lazarow A. Glomerulus basement membrane thickening in diabetes. In Ostman J, Milner, R D G, eds. Diabetes: Proceedings of the Sixth Congress of the International Diabetes Federation, Stockholm. 30 July -4 August 1967. International Congress Series No. 172. Amsterdam: Excerpta Medica, 1969: 301-6.

13 Chang K, Hitto J, Rowold E A, Grant G A, Kilo C, Williamson $\mathrm{J} R$. Increased collagen crosslinkages in experimental diabetes. Reversal by p-amino-proprionitrile and D-penicillamine. Diabetes 1980; 29: 778-81. 